A purely psychiatric preparation no longer suffices to equip an expert in this field, the author concludes. It is necessary, but is not sufficient ; familiarity with the methods of the psychological laboratory is also required. This is all the more important since criminals must not be divided beforehand into vicious and insane. Every inculpated person should be examined by an expert. This is necessary, not merely to discover those who are, in the ordinary sense, insane, but for the more difficult and important end of ascertaining how far those who are not technically insane are susceptible of medico-psychological treatment. The authors incline to think that all criminals should receive sentence (although their actual presence in court might in some cases be dispensed with); for it is for the judge, representing society, to determine what persons are in their present condition unfit for society, but for all serious offences the indeterminate sentence is the only one that should be permitted. In all cases, also, there should be a preliminary period of observation before the method of treatment is decided and the offender classed. The prison must be a hospital. The medical expert, however, would remain only an expert, and it would be for the judge to sanction or not his recommendations. Not all these ideas, the authors remark, are yet realised, but they are meeting with less and less opposition, and it is becoming generally recognised that simple criminals and insane criminals are not essentially different.

The paper is a clear and vigorous presentation of some of the most recent tendencies in alienism as it affects criminals.

Havelock Ellis.

\title{
A New Classification of Criminals founded on Psycho-pathology [Nuova classificazione dei delinquenti fondata sulla psichopatologia]. (II Manicomio, anno xxi, No. 3, 1905.) Ingegnieros.
}

Defining crime as "a human action which transgresses the conditions of the struggle for existence that are normal to the social milieu," the author considers its scientific study under three aspects : (x) the etiology of crime; (2) clinical criminology, investigating the forms of delinquency and the characteristics of the criminal ; and (3) the therapeutics of crime.

The causes of crime are of two orders, endogenous or biological, and exogenous or dependent on the social or physical environment. The study of the former class constitutes criminal anthropology, which is again divisible into criminal psychopathology and criminal morphology. The investigation of the exogenous factors of crime, which is the province of criminal mesology, is also to be considered under two headsviz., criminal sociology, which deals with the causes belonging to the social environment, and criminal meteorology, which has to do with the influences of the physical environment. The two orders of factors are always associated in the causation of crime, but in proportions that vary widely in different cases ; in the instinctive criminals and the insane criminals, for instance, the predominance of the biological factors is evident ; while in the category of the occasional criminals the chief part belongs to the influence of the environment.

Of the three modes of function under which the psychic activity, 
itself one and indivisible, becomes manifest, namely the intellectual, the emotional, and the volitional, one or other is usually predominant in the individual personality, and determines the type of character. In the criminal the anomaly of character, which is revealed in conduct, may be predominant similarly in one or other of these modes of function. Classified on this basis the psychopathic disorders of the criminal may be represented in this scheme :

Moral anomalies (dysthimias).-Congenital : congenital criminals or moral idiots; acquired: habitual or morally perverted criminals; transitory : occasional criminals.

Intellectual anomalies (dysgnosias).-Congenital : criminals from constitutional mental defect; acquired: criminals from acquired insanity; transitory : drunkards and other forms of toxic insanity.

Volitional anomalies (dysbulias).-Congenital : impulsive epileptics; acquired : impulsive chronic alcoholics; transitory: criminals from passion.

To these three groups, which represent pure types, it is necessary to add a fourth, formed by the combined types in which the loss of functional balance affects more than one psychic sphere; thus we have sensitivo-intellectual criminals in whom ethical defect is associated with intellectual defect, and volitional-intellectual criminals who are lacking in power of inhibition at the same time as they are intellectually feeble, while again we meet with cases of extreme degeneration in which impulsiveness, absence of moral sense, and intellectual weakness co-exist ; these latter represent the psychologically complete type of the criminal.

W. C. Sullivan.

Relationships between Somatic Anomalies and the Educational Capacity of the Senses in the Defective [Rapporti fra $i$ caratteri anomali somatici e leducabilitid dei sensi nei deficienti]. (Arch. di Psichiat., vol. xxvii, fasc. $i$-ii, 1905.) Montesano and Selvatico-Estense.

This very valuable paper is based on an exhaustive study of fifty mentally defective children (thirty males and twenty females) in the asylum of Santa Maria della Pietà at Rome. The method pursued by the authors was to establish in each case on the one hand the number and character of the somatic anomalies, and on the other the degree of educational aptitude for the senses of sight, touch, and hearing, and then to compare the two series of data. Adopting with slight modification Morselli's classification, they divide the physical anomalies into ( $\mathrm{I}$ ) those of a properly degenerative type, recalling conditions found normally in the lower races or in the primates-such, for instance, as "l'oreille en anse," the lemurian apophysis, the prehensile foot, etc. ; (2) those of a mixed or dubious character, probably for the most part of pathological origin, but by some counted among the atavistic stigmata, such as platicephaly, oxycephaly, the Gothic palate, etc. ; and (3) those of distinctively pathological nature, depending either on such dystrophic processes as cause facial symmetry, strabismus, etc., or on constitutional diseases of which rickets is the most important, or on accidental circumstances such as injury at birth or in childhood, meningo-encephalitis, and so forth. 